\title{
Comparison of multiplexed reduced representation bisulfite sequencing (mRRBS) with the 450K Illumina Human BeadChip: from concordance to practical applications for methylomic profiling in epigenetic epidemiologic studies
}

\author{
Juan J Carmona ${ }^{1,2,3}$, Benedetta Izzi ${ }^{4,5}$, Allan C Just $^{1 *}$, Jitendra Barupal ${ }^{1}$, Alexandra M Binder ${ }^{3}$, John Hutchinson ${ }^{6}$, \\ Oliver Hofmann ${ }^{6}$, Joel Schwartz ${ }^{1,2,3}$, Andrea Baccarelli ${ }^{1,2,3,7,8}$, Karin B Michels $s^{3,4,5}$ \\ From Epigenetics and Chromatin: Interactions and processes \\ Boston, MA, USA. 11-13 March 2013
}

\section{Background}

Reduced representation bisulfite sequencing (RRBS) is an efficient approach for large-scale base-pair resolution DNA methylation analysis. RRBS utilizes Mspl digestion to enrich for CpG dinucleotides prior to sequencing. RRBS works with considerably lower amounts of DNA compared to the human 450K BeadChip Illumina microarray. Previous studies have compared these two methodologies with good concordance on a relatively small set of overlapping sites. Boyle and colleagues recently proposed a variant of RRBS which is gel-free and high-throughput, allowing for the simultaneous processing of multiple samples [1]. Given the potential of mRRBS to characterize the methylome in larger epidemiology studies, there is a need to compare the performance of the multiplexed RRBS (mRRBS) with the 450K BeadChip, especially in terms of reproducibility of the results and genomic coverage.

\section{Materials and methods}

We have compared mRRBS with the 450K BeadChip using buffy coat genomic DNA extracted from 24 samples from 12 males in an existing cohort. Additionally, 6 of the 24 samples were replicated in the mRRBS study as analytic duplicates. A further 12 samples were sequenced again at a higher cluster density. Sequencing with 75bp single-end reads used both 6 or 12 sample pools on the Illumina HiSeq 2000. Post-processing included read trimming with Trim Galore, alignment using Bismark, and merging of informative reads from both strands for CpGs. Data from the $450 \mathrm{k}$ beadchip were normalized using a recent comprehensive pipeline [2].

\section{Results}

Among 42 samples sequenced, 28 had more than $5 \mathrm{M}$ reads and after alignment of $>71 \%$ of trimmed reads, these samples had a median of $1.3 \mathrm{M} \mathrm{CpGs}$ at $\geq 10 \mathrm{x}$ depth (300K to $2.5 \mathrm{M} \mathrm{CpGs)}$. Samples $<5$ million reads were related to particular Illumina sequencing adapters and position on the library preparation plate. Sequencing at a higher cluster density yielded $\sim 300 \mathrm{~K}$ extra CpGs at $>10 \mathrm{x}$ depth. To represent a population, we took the best passing sample ( $>5 \mathrm{M}$ reads, $\mathrm{n}=11$ ) from each individual. There were $160 \mathrm{~K}$ shared sites among all 11 samples at $\geq 10 \mathrm{x}$ depth with $1 \mathrm{M}$ found in 8 of 11 . Between $24 \mathrm{~K}$ and $124 \mathrm{~K}$ sites per sample overlapped with Illumina $450 \mathrm{~K}$ sites. Pearson correlation coefficients between RRBS \%methylation ( $\geq 10 \mathrm{x}$ depth) and quantile normalized $450 \mathrm{~K}$ beta values for these 11 samples ranged from 0.92 to 0.95 . 


\section{Conclusions}

Given the observed differences in reads by library position and adapter ligation efficiency, a more even distribution of reads per sample may be achieved by screening adapters and concentration matching prior to pooling samples. These results support the use of mRRBS for methylomics in epigenetic epidemiologic studies, and further investigation of sample quality and measurement variability is ongoing.

\section{Author details}

'Laboratory of Environmental Epigenetics, Department of Environmental Health, Harvard School of Public Health, Boston, MA, USA. ${ }^{2}$ Exposure, Epidemiology, \& Risk Program, Department of Environmental Health, Harvard School of Public Health, 401 Park Drive, Landmark Center West, Boston, MA, USA. ${ }^{3}$ Harvard School of Public Health, Department of Epidemiology, Boston, MA, USA. ${ }^{4}$ Obstetrics and Gynecology Epidemiology Center, Department of Obstetrics and Gynecology, Brigham and Women's Hospital, Harvard Medical School, Boston, MA, USA. ${ }^{5}$ Division of Cancer Epidemiology, Comprehensive Cancer Center Freiburg, Freiburg University, Freiburg, Germany. ${ }^{6}$ Center for Health Bioinformatics, Harvard School of Public Health, Department of Biostatistics \& Program in Quantitative Genomics, Boston, MA, USA. ${ }^{7}$ DanaFarber/Harvard Cancer Center, Boston, MA, USA. ${ }^{8}$ Harvard/Massachusetts General Hospital Center on Genomics, Vulnerable Populations, and Health Disparities, Boston, MA, USA.

Published: 18 March 2013

\section{References}

1. Boyle P, Clement K, Gu H, Smith ZD, Ziller M, Fostel JL, Holmes L, Meldrim J, Kelley F, Gnirke A, Meissner A: Gel-free multiplexed reduced representation bisulfite sequencing for large-scale DNA methylation profiling. Genome Biol 2012, 13:R92.

2. Touleimat N, Tost J: Complete pipeline for Infinium((R)) Human Methylation 450K BeadChip data processing using subset quantile normalization for accurate DNA methylation estimation. Epigenomics 2012, 4:325-341

doi:10.1186/1756-8935-6-S1-P36

Cite this article as: Carmona et al:: Comparison of multiplexed reduced representation bisulfite sequencing (mRRBS) with the 450K Illumina Human BeadChip: from concordance to practical applications for methylomic profiling in epigenetic epidemiologic studies. Epigenetics \& Chromatin 2013 6(Suppl 1):P36.

\section{Submit your next manuscript to BioMed Central and take full advantage of:}

- Convenient online submission

- Thorough peer review

- No space constraints or color figure charges

- Immediate publication on acceptance

- Inclusion in PubMed, CAS, Scopus and Google Scholar

- Research which is freely available for redistribution

Submit your manuscript at www.biomedcentral.com/submit
C Biomed Central 